\title{
Version 2.1 of the International Spinal Cord Injury Bowel Function Basic Data Set
}

\author{
Klaus Krogh ${ }^{1} \cdot$ Annette Halvorsen $^{2} \cdot$ Ann Louise Pettersen ${ }^{3} \cdot$ Fin Biering-Sørensen ${ }^{4}$
}

Received: 18 June 2019 / Accepted: 26 June 2019

(c) International Spinal Cord Society 2019

In the process of translation of the English version into Nordic languages (Danish, Icelandic, Norwegian, and Swedish) of the International Spinal Cord Injury Bowel Function Basic Data Set version 2.0 [1] some inconsistencies were recognized which here will be corrected and clarified:

1. For the variable "Surgical procedures on the gastrointestinal tract":

In the data-collection form 'Hemorrhoidectomy, date performed YYYYMMDD' was missing

2. The variable: "Frequency of defecation (within the last 4 weeks)"

a. In the description in the syllabus and in the Datacollection form should the code 'Once or more per day' be changed to 'Daily', '2-6 times per week' be changed to ' $1-6$ times per week', and 'Once per week or less' to be changed to 'Less than once per week' to be in accordance with the original neurogenic bowel dysfunction score.

b. In the Data-collection form 'Not applicable' is missing.

3. The variable: "Frequency of fecal incontinence (within the last 4 weeks)"

In the Data-collection form "Less than once per month/Never" shall be together in one code, because the variable is describing the frequency "within the

Fin Biering-Sørensen

fin.biering-soerensen@ regionh.dk

1 Department of Hepatology and Gastroenterology, Aarhus University Hospital, Aarhus, Denmark

2 Department of Medical Quality Registries and Department of Spinal Cord Injuries, St Olavs hospital, Trondheim University Hospital, Trondheim, Norway last 4 weeks' - which is also the description given in the Syllabus.

4. The variable: "Need to wear diaper, pad, or plug (within the last 4 weeks)"

a. The description made regarding the change is correct.

b. The description made in the syllabus should only have the codes:

- No

- Yes

- Not applicable

- Unknown

c. In the Data-collection form 'Not applicable' is missing.

5. The variable: "Perianal problems (within the last 4 weeks)"

Rectal prolapse is removed from the Syllabus as it already was from the Data-collection form

6. The variable: "Abdominal pain and discomfort (within the last 4 weeks)"

The codes in the Syllabus and the Data-collection form are now the same: The code 'Once per week or less' is changed to 'Less than once per week' because otherwise once per week was included in two answers: 
- Daily

- 1-6 times per week

- Less than once per week

- Never

- Unknown

7. If a variable includes the code 'Not applicable' it now consistently inserted before the code 'Unknown'.

These are now also available on the website of the International Spinal Cord Society:

https://www.iscos.org.uk/international-sci-bowel-datasets under the International Spinal Cord Injury Bowel Function Basic Data Set Version 2.1.

\section{Compliance with ethical standards}

Conflict of interest The authors declare that they have no conflict of interest.

Publisher's note: Springer Nature remains neutral with regard to jurisdictional claims in published maps and institutional affiliations.

\section{References}

1. Krogh K, Emmanuel A, Perrouin-Verbe B, Korsten MA, Mulcahey MJ, Biering-Sørensen F. International spinal cord injury bowel function basic data set (Version 2.0). Spinal Cord 2017;55:692-8. https://doi.org/10.1038/sc.2016.189. 